\title{
Multidrug Resistant Bacteria in Urinary Tract Infection: A Constant Threat to a Tertiary Care Health Set-up in North India
}

\author{
${ }^{1}$ Sanjay S Kaira, ${ }^{2}$ Anuradha Makkar, ${ }^{3}$ Pragyan S Panda, ${ }^{4}$ Priyanka Banerjee, ${ }^{5}$ ID Khan
}

\begin{abstract}
Introduction: Urinary tract infections (UTIs) is one of the most common bacterial infections. Irrelevant use of antibiotics has resulted in the emergence of resistant strains.
\end{abstract}

Aims and objective: To identify and look for the antimicrobial resistance pattern of various isolates in a tertiary care teaching hospital.

Methods: A retrospective study was conducted in a tertiary level hospital for 4 years (March 2014 to March 2018). A total of 41020 urine samples received in the laboratory and 6114 of them diagnosed to be culture positive UTI were processed for Antibiotic sensitivity by the standard microbiological procedure.

Results: Out of 6114 culture, positive samples 2829 (46.27\%) had significant bacteriuria. Females more affected $(52.27 \%)$ than males (48.43\%). Amongst fermenters (GNF), E.coli $(52.7 \%)$ was most common followed by Klebsiella spp. (23.65\%). Amongst the Gram-positive organisms Enterococcus spp. (3.67\%) was more common followed by Staphylococcus saprophyticus (1.44\%). While Pseudomonas spp. followed by Burkholderia sp were the common non-fermenters (GNNF). In GNF, imipenem, meropenem and amikacin were most effective drugs whereas, in GNNF, imipenem, meropenem and piperacillin- tazobactam were more effective. Linezolid and vancomycin were the most sensitive antibiotics in Gram-positive isolates.

Conclusion: There is increasing resistance to, and nitrofurantoin noted in our study that is frequently considered drugs of choice for empiric therapy. It is important to determine trends in antimicrobials susceptibilities, to formulate local antibiotics policy that will guide the clinicians regarding the empirical choice for UTI to prevent misuse or overuse of antibiotics.

Clinical significance: Because of the emerging resistance to the available group of antimicrobials, regular monitoring of the resistance pattern is essential for the clinicians to choose for the best empiric therapy.

Keywords: Antimicrobial resistance, Nonfermenters, Urinary tract infections (UTIs)

How to cite this article: Kaira SS, Makkar A, Panda PS, Banerjee P, Khan, ID. Multidrug Resistant Bacteria in Urinary Tract Infection: A Constant Threat to a Tertiary Care Health Set-up in North India. Journal of Medical Academics 2018;1(1):15-21.

\footnotetext{
${ }^{1,3}$ Tutor, ${ }^{2}$ Professor and Head, ${ }^{4}$ Assistant Professor, ${ }^{5}$ Associate Professor

${ }^{1-5}$ Army College of Medical Sciences, Delhi Cantt, India

Corresponding Author: Anuradha Makkar, Professor and Head, Army College of Medical Sciences, Delhi Cantt, India, e-mail: anuradhamakkar@hotmail.com
}

\section{Source of support: Nil}

Conflict of interest: None

\section{INTRODUCTION}

Urinary tract infections (UTIs), one of the most common bacterial infections in the community as well as hospital setting affecting people of all age group represents a major source of human distress and morbidity. ${ }^{1,2}$

The irrelevant use of antibiotics has resulted in the emergence of resistant strains. Besides extendedspectrum beta-lactamase (ESBL), metallo-beta-lactamase (MBL) and Amp-C mediated beta-lactamase by Enterobacteriaceae members, the uropathogens are also exhibiting increased resistance to antibiotics like nitrofurantoin, co-trimoxazole, and quinolones which are used as oral antibacterial options for treating UTIs in community settings. ${ }^{3}$ Hospital-acquired UTI is a serious threat especially for the immuno-deficient patients laying a significant economic burden on the patient as well as the hospital administrations. ${ }^{1}$ Multidrug-resistant UTIs has compelled the clinicians to shift to carbapenems, colistin and other higher and reserved antibiotics. ${ }^{4}$ Prevalence of pan-resistance have also increased leaving no therapeutic options for the patients.

Gram-negative bacteria of Enterobacteriaceae family like Escherichia coli, Klebsiella pneumoniae and Proteus mirabilis and Gram-positive organisms Staphylococcus aureus, Enterococcus faecalis, Staphylococcus saprophyticus, and other coagulase-negative staphylococcus (CONS) are the most common ones causing UTI. ${ }^{5}$ Pseudomonas spp., Acinetobacter spp. are more commonly isolated Non- fermenters causing UTI. ${ }^{6}$

Because of the evolving and on-going change in microbial resistance to the available group of antimicrobials, regular monitoring of resistant patterns is essential for up gradation of the empirical antibiotics therapy guidelines. ${ }^{7}$ The current study aimed to determine the various types of bacterial isolates cultured from UTIs patients and to look for their antimicrobial resistance pattern in a tertiary care teaching hospital. 


\section{MATERIALS AND METHODS}

A retrospective study was performed on 41020 clinically suspected patients having UTI in a tertiary care teaching hospital over a period of 4 years (March 2014 to March 2018). Out of which 6114 were diagnosed with culture-positive UTI. Repeat samples from the same patients and non-culture positive were excluded. Clean catch mid-stream urine sample was collected in a sterile, wide-mouthed screw caps containers and transported to the laboratory as quickly as possible. ${ }^{3,8}$ A sterile $4 \mathrm{~mm}$ nichrome calibrated loop was used which delivers 0.01 $\mathrm{mL}$ of urine and semi-quantitative culture was done on cysteine lactose electrolyte deficient agar (CLED) using standard microbiological techniques and the plate was incubated aerobically overnight at $37^{\circ} \mathrm{C}$ for 24 hours. The number of isolated bacterial colonies was multiplied by 100 for the estimation of bacterial load/mL of the urine sample. ${ }^{9}$ Identification and antibiogram was done by Vitek 2 compact (Biomerieux, France) system. Wherever required conventional techniques were also performed as per the standard guidelines.

\section{Statistics}

The statistical analysis was performed using statistical package for the social sciences (SPSS) software version 16.0. Data were presented as percentages and proportions.

\section{RESULTS}

In the current study, 6114 urine samples were culture positive, out of which $2829(46.27 \%)$ had significant bacteriuria. Out of these, 255(9.01\%) samples showed growth of two type of organisms, while from remaining 2574 (90.98\%) of the samples only one organism was isolated. ${ }^{7}$ Female patients were affected in 1479 (52.27\%) cases while $1370(48.43 \%)$ were males. The male:female ratio was 0.9:1 (Table 1).

The UTI was more commonly prevalent in females of 21 to 30 years (50.03\%) age group followed by 31 to 40 years $(20.49 \%)$ of age while in males, $>50$ years $(46.42 \%)$ age group was more commonly affected followed by 31 to 40 years $(18.25 \%)$ age group (Table 1$)$. Gram-negative fermenters were found in $82.86 \%$ and non-fermenters

Table 1: Gender wise distribution of patients with UTI ( $N=2829)$

\begin{tabular}{lll}
\hline Age group & Male & $\begin{array}{l}\text { Female } \\
N(\%)\end{array}$ \\
& $104(7.6 \%)$ & $19(1.3 \%)$ \\
\hline $0-10$ & $40(2.9 \%)$ & $123(8.4 \%)$ \\
$11-20$ & $210(15.3 \%)$ & $730(50.03 \%)$ \\
$21-30$ & $250(18.25 \%)$ & $299(20.49 \%)$ \\
$31-40$ & $130(9.5 \%)$ & $123(8.4 \%)$ \\
$41-50$ & $636(46.42 \%)$ & $165(11.30)$ \\
$>50$ & $1370(48.43 \%)$ & $1459(52.27 \%)$ \\
Total $(\mathrm{N}=2829)$ & & \\
\hline
\end{tabular}

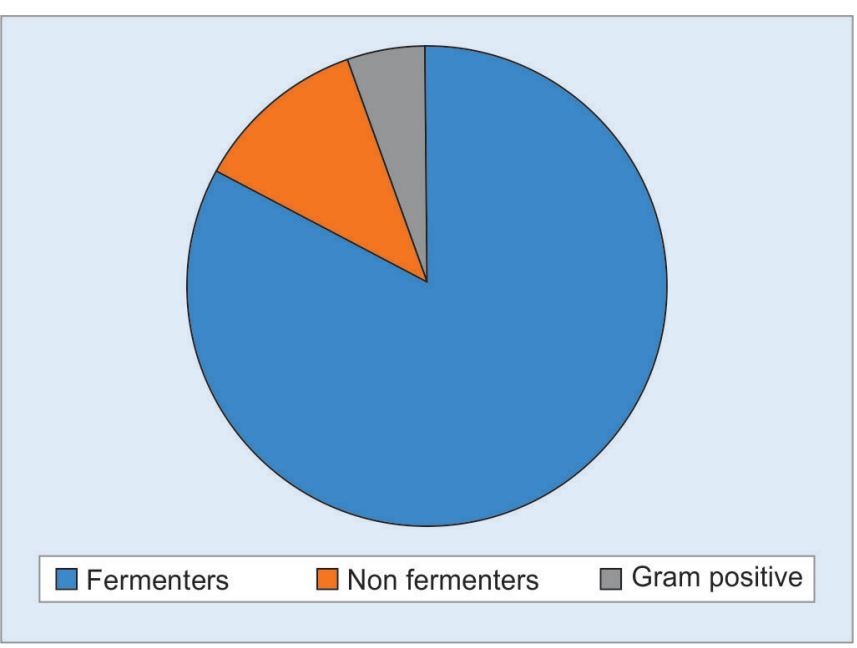

Graph 1: Distribution of organisms ( $=2829)$

in $11.66 \%$ of the sample while Gram-positive organisms were isolated in $5.48 \%$ of cases (Graph 1).

Out of the total 2829 samples, E.coli (52.7\%) was the most common bacteria isolated in all the age groups and both sexes followed by Klebsiella sp (23.65\%), Pseudomonas spp. (7.35\%). Amongst the Gram-positive organisms Enterococcus spp. (3.67\%) were more common follow by Staphylococcus saprophyticus (1.44\%) and S. aureus (0.35\%) (Graph 2).

The antibiotic sensitivity pattern of Gram-negative fermenters $(\mathrm{N}=2344)$ shows that the most commonly sensitive antibiotic against all the pathogens is imipenem (79.5\%), meropenem (79.4\%), Amikacin (64.5\%) followed by piperacillin/tazobactam (44.1\%)and gentamicin $(39.8 \%)$. The organisms showed variable resistance to cefoperazone/sulbactam, ampicillin/sulbactam, ceftriaxone and fluoroquinolones (Table 2).

Antibiotic sensitivity pattern of the Gram-negative Non-fermenters $(\mathrm{N}=330)$ is shown in Table 3. Most common Non-fermenters isolated were Pseudomonas spp, Burkholderia spp. followed by Acinetobacter spp. They displayed variable sensitivity to different groups of antibiotics as shown in Table 3. The most effective antibiotic against the non-fermenters was imipenem, Meropenem, Piperacillin-tazobactam and levofloxacin $n$ few of the organism. (It is recommended as group A and group B antibiotic in certain organisms as per CLSI, so was used in the panel of antibiotics tested)

The antibiotic sensitivity pattern of the gram-positive organisms $(\mathrm{N}=155)$ shown in Table 4. Enterococcus spp. is the most common Gram-positive organisms isolated followed by CONS and S. aureus. Linezolid and Vancomycin were the most sensitive antibiotic, followed by nitrofurantoin (Urinary isolates only), cotrimoxazole, and tetracycline. Ampicillin and fluoroquinolones were not very much effective against the Gram-positive isolates. 


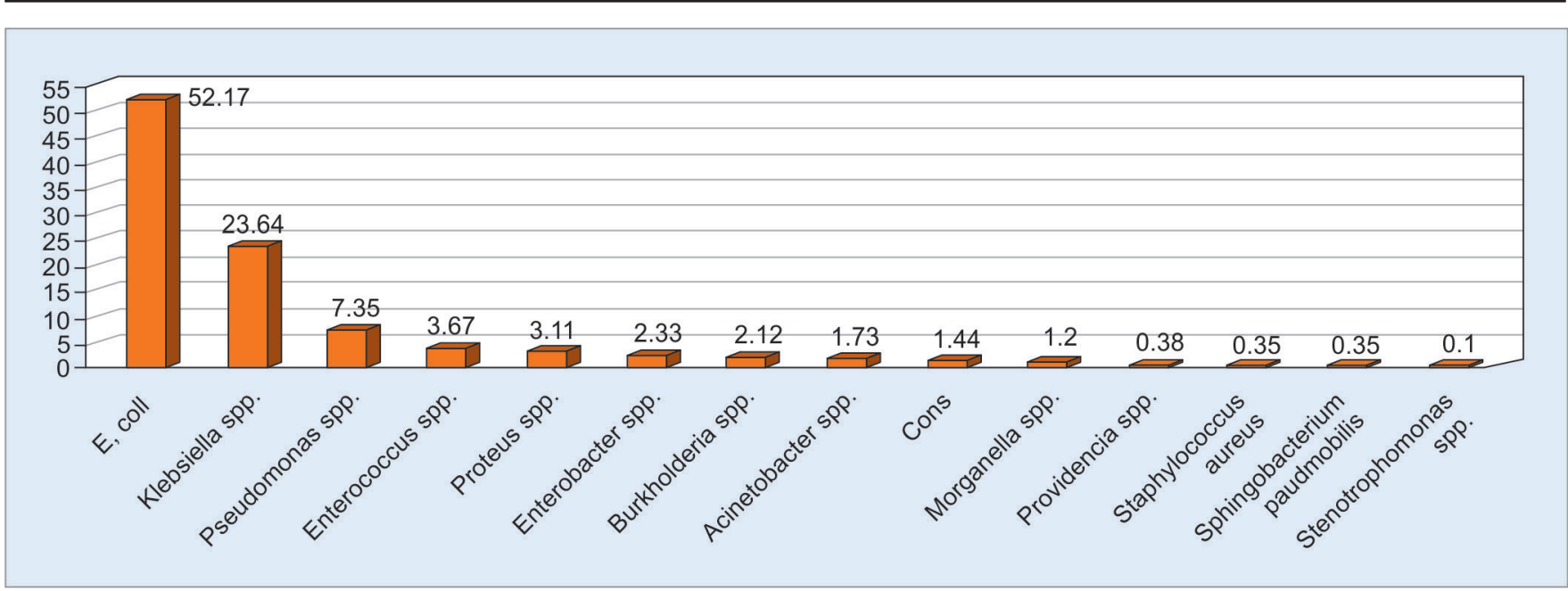

Graph 2: Spectrum of organisms isolated from patients with UTI ( $N=2829)$

Table 2: Antibiotics sensitivity pattern of Gram negative (fermenters) $(N=2344)$

\begin{tabular}{lllllll}
\hline & $\begin{array}{l}\text { E.coli } \\
(n-1476)\end{array}$ & $\begin{array}{l}\text { Klebsiella } \\
\text { spp. } \\
(n-669)\end{array}$ & $\begin{array}{l}\text { Enterobacter spp. } \\
(n-66)\end{array}$ & $\begin{array}{l}\text { Proteus spp. } \\
(n-88)\end{array}$ & $\begin{array}{l}\text { Providencia } \\
\text { spp. } \\
(n-11)\end{array}$ & $\begin{array}{l}\text { Morganella } \\
\text { spp. } \\
(n-34)\end{array}$ \\
\hline Antibiotics & $1230(83.33 \%)$ & $323(48.28 \%)$ & $31(46.9 \%)$ & $55(62.5 \%)$ & 0 & $22(64.7 \%)$ \\
Azteronam & $331(22.42 \%)$ & $112(16.74 \%)$ & $20(30.3 \%)$ & $24(27.2 \%)$ & $03(27.2 \%)$ & $19(55.9 \%)$ \\
Ciprofloxacin & $222(15.04 \%)$ & $138(20.62 \%)$ & $23(34.9 \%)$ & $18(20.4 \%)$ & 0 & $05(14.7 \%)$ \\
Ceftriaxone & $363(24.6 \%)$ & $115(17.19 \%)$ & $20(30.3 \%)$ & $28(31.8 \%)$ & $4(36.3 \%)$ & $15(44.1 \%)$ \\
Nitrofurantoin & $718(48.6 \%)$ & $74(11.06 \%)$ & $05(7.5 \%)$ & NA & NA & NA \\
Gentamicin & $704(47.7 \%)$ & $222(33.2 \%)$ & $26(39.45)$ & $35(39.8 \%)$ & $4(36.3 \%)$ & $16(47.05 \%)$ \\
Imipenem & $1446(97.8 \%)$ & $333(49.8 \%)$ & $30(45.5 \%)$ & $70(79.5 \%)$ & $7(63.7 \%)$ & $25(73.5 \%)$ \\
Meropenem & $1448(98.10 \%)$ & $352(52.6 \%)$ & $36(54.5 \%)$ & $77(87.5 \%)$ & $8(72.7 \%)$ & $27(79.4 \%)$ \\
Cefoperazone/ Sulbactum $)$ & $66(6.8 \%)$ & $2(18.1 \%)$ & $6(17.6 \%)$ \\
Ampicillin/Sulbactum & $67(4.53 \%)$ & $90(13.5 \%)$ & $15(23 \%)$ & & & \\
Pipercillin/Tazobactam & $328(22.22 \%)$ & $109(16.3 \%)$ & $13(19.6 \%)$ & $54(61.3 \%)$ & $6(54.5 \%)$ & $18(52.9 \%)$ \\
\hline
\end{tabular}

\section{DISCUSSION}

Currently, UTI is one of the most common infection encountered in clinical practice, and antimicrobial resistance is a serious concern in the treatment of symptomatic UTI. ${ }^{6}$ The most effective management of UTI patients commonly depend on the identification of the bacterial isolate and the selection of an effective antibiotic agent against them. ${ }^{8}$ Antimicrobial resistance is a serious public health threat nowadays. Resistance developed by different bacterial pathogens against commonly used antimicrobials causing treatment failure and morbid outcomes. ${ }^{1}$

In this study, most of the urinary isolates were from female patients $(52.27 \%)$, and the prevalence was more common in the age group of 21 to 30 years. The result was similar to that found by Kaira et al. ${ }^{2}$ and many other studies in India. It is considered due to the short urethra and its close proximity to the anus in the case of female patients.

In the current study, E.coli was found to be the most common isolate causing UTI. In a study conducted in Meerut, India (2013) by Prakash et al. ${ }^{8}$ and in Lahore, Pakistan in 2014 by Khan et al., ${ }^{1}$ E. coli was the most common bacteria, accounting for $42.71 \%$ and $61.3 \%$ of the total culture positive isolates respectively. While in two other studies carried out in Canada and Ethiopia in recent years the occurrence of $E$. coli as the causative agent of UTIs was found to be 80 to $90 \% .{ }^{10,11}$ In the current study, the second most common urinary isolate was Klebsiella spp.which is similar to a study conducted by Prakash et al. ${ }^{6}$ and Farajnia et al. ${ }^{8}$ However, it was in contrary to other studies where the second commonest reported isolates were Pseudomonas spp. ${ }^{1}$

In the current study, the most commonly sensitive antibiotic against all the pathogens is imipenem (79.5\%), meropenem $(79.4 \%)$, amikacin $(64.5 \%)$ followed by piperacillin/tazobactam (44.1\%) gentamicin (39.8\%). The organisms showed variable resistance to cefoperazone/ sulbactam, ampicillin/sulbactam, ceftriaxone, and fluoroquinolones. In the study by Panda et al. ${ }^{6}$ isolates were resistant to ampicillin, amoxicillin-clavulanic acid, and aztreonam while they were most sensitive to imipenem, gentamicin, and nitrofurantoin. As far as the antimicrobial sensitivity of quinolones to $E$. coli is concerned, the susceptibility to ciprofloxacin was $15.04 \%$ in our study 
Table 3: Antibiotics sensitivity pattern of Gram negative (non-fermenters) ( $\mathrm{N}=330)$

\begin{tabular}{|c|c|c|c|c|c|}
\hline Antibiotics & $\begin{array}{l}\text { Pseudo- } \\
\text { monas } \\
\text { spp. } \\
\text { (n-208) }\end{array}$ & $\begin{array}{l}\text { Acineto- } \\
\text { bacter } \\
\text { spp. } \\
(n-49)\end{array}$ & $\begin{array}{l}\text { Burkhol- } \\
\text { deria } \\
\text { spp. } \\
(n-60)\end{array}$ & $\begin{array}{l}\text { Sphingo- } \\
\text { monas } \\
\text { spp. } \\
(n-10)\end{array}$ & $\begin{array}{l}\text { Stenotro- } \\
\text { phomonas } \\
\text { spp. } \\
(n-03)\end{array}$ \\
\hline Amikacin & $\begin{array}{l}69 \\
(33.1 \%)\end{array}$ & $\begin{array}{l}8 \\
(16.3 \%)\end{array}$ & $\begin{array}{l}11 \\
(18.3 \%)\end{array}$ & $7(70 \%)$ & - \\
\hline Aztreonam & $\begin{array}{l}11 \\
(5.2 \%)\end{array}$ & $\begin{array}{l}11 \\
(22.4 \%)\end{array}$ & $\begin{array}{l}02 \\
(3.33 \%)\end{array}$ & $2(20 \%)$ & - \\
\hline Nitrofurantoin & $\begin{array}{l}28 \\
(13.4 \%)\end{array}$ & 0 & - & $3(30 \%)$ & - \\
\hline Gentamicin & $\begin{array}{l}57 \\
(27.4 \%)\end{array}$ & $\begin{array}{l}13 \\
(26.5 \%)\end{array}$ & $\begin{array}{l}09 \\
(15 \%)\end{array}$ & $7(70 \%)$ & - \\
\hline Imipenem & $\begin{array}{l}91 \\
(43.7 \%)\end{array}$ & $\begin{array}{l}17 \\
(34.7 \%)\end{array}$ & $\begin{array}{l}10 \\
(16.7 \%)\end{array}$ & $7(70 \%)$ & - \\
\hline Meropenem & $\begin{array}{l}78 \\
(37.5 \%)\end{array}$ & $\begin{array}{l}18 \\
(36.7 \%)\end{array}$ & $\begin{array}{l}32 \\
(53.3 \%)\end{array}$ & $7(70 \%)$ & - \\
\hline Levofloxacin & $\begin{array}{l}05 \\
(2.4 \%)\end{array}$ & $\begin{array}{l}8 \\
(16.3 \%)\end{array}$ & $\begin{array}{l}28 \\
(46.6 \%)\end{array}$ & - & $\begin{array}{l}3 \\
(100 \%)\end{array}$ \\
\hline $\begin{array}{l}\text { Pipercillin/ } \\
\text { tazobactam }\end{array}$ & $\begin{array}{l}89 \\
(42.7 \%)\end{array}$ & $\begin{array}{l}13 \\
(26.5 \%)\end{array}$ & - & $6(60 \%)$ & - \\
\hline $\begin{array}{l}\text { Ampicillin/ } \\
\text { sulbactum }\end{array}$ & - & $\begin{array}{l}11 \\
(22.4 \%)\end{array}$ & $03(5 \%)$ & $7(70 \%)$ & - \\
\hline Ciprofloxacin & $52(25 \%)$ & $\begin{array}{l}10 \\
(20.4 \%)\end{array}$ & $\begin{array}{l}09 \\
(15 \%)\end{array}$ & $6(60 \%)$ & $\begin{array}{l}3 \\
(100 \%)\end{array}$ \\
\hline Tobramycin & $\begin{array}{l}65 \\
(31.25 \%)\end{array}$ & $\begin{array}{l}17 \\
(34.7 \%)\end{array}$ & $\begin{array}{l}10 \\
(16.7 \%)\end{array}$ & $6(60 \%)$ & - \\
\hline Ceftriaxone & - & $\begin{array}{l}9 \\
(18.3 \%) \\
\end{array}$ & $03(5 \%)$ & $7(70 \%)$ & - \\
\hline
\end{tabular}

which is comparable to a study conducted by Majumdar et al. ${ }^{12}$ However, the situation is quite different from $E$. coli isolated in a study carried out by Khameneh et al. ${ }^{4}$ where $83.2 \%$ of bacterial isolates were susceptible to ciprofloxacin. These contrasting results suggest the injudicious use of quinolones in this part of the world which has led to deteriorating susceptibility to this important antimicrobial group. In the current study, $97.8 \%$ of $E$. coli isolates were susceptible to imipenem, the similar study being carried out by Prakash et al. ${ }^{8}$ and Eshwarappa et al. ${ }^{13}$ where $92.68 \%$ and $96 \%$ respectively of $E$. coli isolates were susceptible to imipenem. In our study, the susceptibility of E. coli to nitrofurantoin was $48.6 \%$ which is
Table 4: Antibiotics sensitivity pattern of Gram positive cocci $(\mathrm{N}=155)$

\begin{tabular}{|c|c|c|c|}
\hline Antibiotics & $\begin{array}{l}\text { Staphylococcus } \\
\text { aureus } \\
(n-10)\end{array}$ & $\begin{array}{l}\text { CONS } \\
(n-41)\end{array}$ & $\begin{array}{l}\text { Enterocccus } \\
\text { spp. } \\
(n-104)\end{array}$ \\
\hline Ampicillin & $02(20 \%)$ & - & $05(4.8 \%)$ \\
\hline Ofloxacin & $01(10 \%)$ & 05 (12.2\%) & $10(9.6 \%)$ \\
\hline Ciprofloxacin & $02(20 \%)$ & $05(12.2 \%)$ & $10(9.6 \%)$ \\
\hline Vancomycin & 09 (90\%) & 35 (85.4\%) & $68(65.4 \%)$ \\
\hline Linezolid & $10(100 \%)$ & 35 (85.4\%) & $85(81.7 \%)$ \\
\hline Cotrimoxazole & $05(50 \%)$ & $23(56.1 \%)$ & $53(50.9 \%)$ \\
\hline Nitofurantoin & $09(90 \%)$ & $35(85.4 \%)$ & $53(50.9 \%)$ \\
\hline Gentamicin & $09(90 \%)$ & $17(41.5 \%)$ & NA \\
\hline Tetracycline & $07(70 \%)$ & $18(43.9 \%)$ & $17(16.3 \%)$ \\
\hline $\begin{array}{l}\text { High level } \\
\text { Gentamicin }\end{array}$ & NA & NA & $23(22.1 \%)$ \\
\hline
\end{tabular}

much lower than other study conducted by Majumdar et al. ${ }^{12}$ and Prakash et al. ${ }^{9}$ where only $11.2 \%$ and 23.76 $\%$ respectively of E.coli isolates showing the resistance. Nitrofurantoin is effective against many Gram-positive and Gram-negative urinary isolates and activity of this antimicrobial are greatly enhanced at acidic $\mathrm{pH}$. It is a cheap antimicrobial, easily available and can be given orally for months for the suppression of chronic UTIs. In the current study, E. coli also showed the resistance to nitrofurantoin which is still effective against other urinary isolates and common oral antibiotics for UTIs and can be used prophylactically for recurrent UTIs.

Amikacin and Nitrofurantoin are the recommended antibiotics to treat UTIs caused by Klebsiella spp. Most of the Klebsiella spp.(23.64\%)in our study were sensitive to Meropenem(52.6\%) followed by Imipenem $(49.8 \%)$ and Amikacin $(48.2 \%)$, but they showed greater resistance to Nitrofurantoin (11.06\%) followed by cefoperazone/ Sulbactam(13.5\%). The antimicrobial susceptibility of Enterobacteriaceaerevealed that imipenem was the most effective antibiotic. Comparative resistance pattern of different Fermenters in the different study is given in Table 5

Nonfermenting Gram-negative bacilli (NFGNB), which are saprophytic in nature, have emerged as

Table 5: Comparative study of Gram-negative fermenters organims

\begin{tabular}{|c|c|c|c|c|c|c|c|c|c|c|c|}
\hline \multirow[b]{2}{*}{ S. No. } & \multirow{2}{*}{$\begin{array}{l}\text { Place of sudy } \\
\text { and year }\end{array}$} & \multirow[b]{2}{*}{ Author } & \multirow{2}{*}{$\begin{array}{l}\text { Org. prevalence } \\
(\%)\end{array}$} & \multicolumn{8}{|c|}{ Antibiotics sensitivity } \\
\hline & & & & GEN & $A K$ & PIT & CIP & $L E$ & CTR & $I M I$ & NIT \\
\hline \multirow[t]{4}{*}{1.} & \multirow{4}{*}{$\begin{array}{l}\text { U.P } \\
(2013)\end{array}$} & \multirow{4}{*}{$\begin{array}{l}\text { Prakash } \\
\text { et al. }^{8}\end{array}$} & E.C (42.7\%) & $78.4 \%$ & $100 \%$ & - & $34.15 \%$ & $63.41 \%$ & $51.22 \%$ & $92.68 \%$ & $82.93 \%$ \\
\hline & & & K.P (23.9\%) & $73.9 \%$ & $69.6 \%$ & - & $30.4 \%$ & $100 \%$ & $69.6 \%$ & $30.4 \%$ & $73.9 \%$ \\
\hline & & & Pr. $(19.7 \%)$ & $46,2 \%$ & $61.5 \%$ & - & $100 \%$ & $100 \%$ & $46.2 \%$ & $100 \%$ & NA \\
\hline & & & Ent. $(13.5 \%)$ & $47.4 \%$ & $26.3 \%$ & - & $78.9 \%$ & $100 \%$ & 00 & $100 \%$ & $47.4 \%$ \\
\hline \multirow[t]{4}{*}{2.} & \multirow{4}{*}{$\begin{array}{l}\text { Pakistan } \\
(2014)\end{array}$} & \multirow[t]{4}{*}{ Khan et al. ${ }^{1}$} & E.C $(61.3 \%)$ & $48.8 \%$ & $85 \%$ & $80.7 \%$ & $21.5 \%$ & - & $46.6 \%$ & $96.2 \%$ & $72.6 \%$ \\
\hline & & & K.P $(9.5 \%)$ & $42.8 \%$ & $47.6 \%$ & $52.3 \%$ & $14.2 \%$ & - & $33.3 \%$ & $76 \%$ & $4.7 \%$ \\
\hline & & & Pr. $(2.27 \%)$ & $40 \%$ & $40 \%$ & $100 \%$ & 0 & - & $20 \%$ & $80 \%$ & NA \\
\hline & & & Ent. $(3.18 \%)$ & $42.8 \%$ & 0 & $85.7 \%$ & $28.6 \%$ & - & $57 \%$ & $100 \%$ & $42.8 \%$ \\
\hline \multirow[t]{4}{*}{3.} & \multirow{4}{*}{$\begin{array}{l}\text { Delhi } \\
\text { (Our study) }\end{array}$} & \multirow[t]{4}{*}{-} & E.C $(52.17 \%)$ & $47.7 \%$ & $83.3 \%$ & $41.4 \%$ & $15.1 \%$ & - & $24.6 \%$ & $97.8 \%$ & $48.6 \%$ \\
\hline & & & K.P $(23.64 \%)$ & $33.2 \%$ & $48.3 \%$ & $27.1 \%$ & $20.6 \%$ & - & $17.2 \%$ & $49.8 \%$ & $11.1 \%$ \\
\hline & & & Pr. (3.11\%) & $39.8 \%$ & $62.5 \%$ & $63.6 \%$ & $20.4 \%$ & - & $31.8 \%$ & $79.5 \%$ & NA \\
\hline & & & Ent. $(2.33 \%)$ & $39.5 \%$ & $46.9 \%$ & $36.4 \%$ & $34.9 \%$ & - & $30.3 \%$ & $45.5 \%$ & $07.5 \%$ \\
\hline
\end{tabular}


important healthcare-associated pathogens. They exhibit resistance not only to beta-lactam and the other groups of antibiotics but also to carbapenems. ${ }^{14}$ In our study, most common non-fermenters isolated were Pseudomonas spp, Burkholderia spp. followed by Acinetobacter spp. They displayed variable sensitivity to different groups of antibiotics as shown in Table 3. The most effective antibiotic against the non-fermenters was imipenem, Meropenem, Piperacillin-tazobactam and Levofloxacin in few of the organisms. In a Study by Panda et al., ${ }^{15}$ the Non-fermenters were highly resistant to ceftazidime, cefepime, gentamicin, and ciprofloxacin. However, in contrast to Pseudomonas spp. (highest sensitivity to imipenem), Acinetobacter spp. showed maximum sensitivity to piperacillin-tazobactam and netilmicin. The third most common pathogens causing UTI in our study was Pseudomonas spp., which is as such similar to other studies, conducted by Prakash et al. ${ }^{9}$ Pseudomonas spp. shows high degree resistance to all the routinely used antibiotics including tobramycin (31.25\%) and piperacillin/tazobactam (37.1\%). This is a distressing trend with an indication that Pseudomonas spp. are increasingly developing resistance against carbapenems which is shown in this study where only $34.7 \%$ of isolates showing susceptibility to Imipenem. It is one of the common pathogens causes Nosocomial infection because it is notorious to cause infections at almost all sites and colonized patients develop the disease in the presence of underlying risk factors such as burn wounds, patients with immunosuppression and post surgeries.

The antimicrobial susceptibility of Acinetobacter spp. causing UTI's in this study showed a high degree of resistance to almost all the routinely used antibiotics necessitating its susceptibility testing for newer drugs. All the uropathogens showed high degree of resistance to amikacin (12.2\%), ceftriaxone (18.3\%) and ciprofloxacin $(20.4 \%)$ which is comparable to the study conducted by Khan et al. ${ }^{1}$ This is quite possible due to the opportunistic nature of the organism and its adaptability in causing hospital-acquired infections in hospitalized patients especially those fitted with catheters. Unhygienic practices in hospitals (contaminated hands of staff) and the warm hospital environment (summers) promotes colonization. Besides Pseudomonas spp. and Acinetobacter spp. other non-fermenters which were isolated in our study were Burkholderia (02.12\%), Sphingobacterium spp. $(0.35 \%)$ and Stenotrophomonas $(0.10 \%)$. B. cepacia is high virulent organism usually causing lower respiratory tract infections and may also be a causative pathogen for nosocomial UTI in pediatric patients with predisposing factors. ${ }^{16} \mathrm{~B}$. cepacia is one of the most antimicrobialresistant organisms, with high intrinsic resistance encountered in the clinical laboratory; and such infections can be very difficult to treat. All sixty (2.12\%) urinary B. cepacia complex isolates recovered in our study showed resistance to almost all of the antimicrobial agents except levofloxacin (46.6)\% and ceftazidime (16.6\%). B. cepacia complex strains are multidrug-resistant due to innate and acquired mechanisms of resistance but emerging resistance to these antimicrobial agents is of increasing clinical concern, especially among cystic fibrosis (CF) patients. ${ }^{17}$ There were $10(0.35 \%)$ isolates of Sphingomonas spp. isolated in our study. They were most susceptible to Amikacin (70\%), Gentamicin (70\%), Meropenem (70\%). They are mostly causing hospital-acquired infection. Comparative resistance pattern of different Fermenters in the different study is given in Table 6.

In the current study, Enterococcus spp. is the most common Gram-positive organisms isolated followed by CONS and S. aureus. linezolid and vancomycin were the most sensitive antibiotic, followed by nitrofurantoin, cotrimoxazole, and tetracycline. Ampicillin and fluoroquinolones were not very much effective against the Gram-positive isolates.

In our study, the antibiogram of Enterococcus isolates showed that $85.7 \%$ and $65.9 \%$ of the isolates showed sensitive to Linezolid and Vancomycin respectively. The antimicrobial susceptibility of the enterococcal isolates against ampicillin $(9.6 \%)$ and ciprofloxacin $(9.6 \%)$ was quite low. However, vancomycin and Linezolid-resistant enterococcus was also isolated in this study. In another Study by Panda et al. ${ }^{6}$ the Gram-positive isolates of Enterococcus

Table 6: Comparison of antibiotic sensitivity pattern of Gram-negative non-fermenters

\begin{tabular}{|c|c|c|c|c|c|c|c|c|c|c|c|}
\hline $\begin{array}{l}\text { S. } \\
\text { No. }\end{array}$ & Author name & $\begin{array}{l}\text { Place of study and } \\
\text { year }\end{array}$ & $\begin{array}{l}\text { Org. prevalence } \\
(\%)\end{array}$ & GEN & $A K$ & CIP & $C A Z$ & NIT & TO & $I M I$ & PIT \\
\hline \multirow[t]{2}{*}{1.} & \multirow{2}{*}{$\begin{array}{l}\text { Rangari } \\
\text { et al. } .^{18}\end{array}$} & \multirow{2}{*}{$\begin{array}{l}\text { Muzaffarnagar } \\
(2015)\end{array}$} & Pseud (3\%) & 0 & $33.3 \%$ & 0 & 0 & 0 & 0 & $77.8 \%$ & $88.9 \%$ \\
\hline & & & Acinet $(1 \%)$ & 0 & 0 & 0 & $33.3 \%$ & $100 \%$ & $33.3 \%$ & $100 \%$ & $66.7 \%$ \\
\hline \multirow[t]{2}{*}{2.} & \multirow{2}{*}{$\begin{array}{l}\text { Bhatt P } \\
\text { et al. }{ }^{19}\end{array}$} & \multirow[t]{2}{*}{ Pune (2017) } & Pseud $(5.6 \%)$ & $46 \%$ & - & $45 \%$ & $14 \%$ & - & - & $54 \%$ & $21 \%$ \\
\hline & & & Acinet $(2.6 \%)$ & $24 \%$ & - & $19 \%$ & $19 \%$ & - & - & $33 \%$ & $10 \%$ \\
\hline \multirow[t]{2}{*}{3.} & \multirow[t]{2}{*}{ Khan et al. ${ }^{1}$} & \multirow{2}{*}{$\begin{array}{l}\text { Rawalpindi } \\
\text { (2014) }\end{array}$} & Pseud (11.8\%) & $7.7 \%$ & $26.9 \%$ & $15.4 \%$ & $57.7 \%$ & - & - & $65.3 \%$ & $73 \%$ \\
\hline & & & Acinet $(2.3 \%)$ & - & $20 \%$ & $40 \%$ & - & - & - & $20 \%$ & $80 \%$ \\
\hline \multirow[t]{2}{*}{4.} & \multirow[t]{2}{*}{ Our study } & \multirow[t]{2}{*}{ Delhi } & Pesud $(7.35 \%)$ & $27.4 \%$ & $33.1 \%$ & $25.5 \%$ & - & $13.4 \%$ & $31.25 \%$ & $43.7 \%$ & $42.7 \%$ \\
\hline & & & Acinet $(1.73 \%)$ & $21.5 \%$ & $11.3 \%$ & $20.4 \%$ & - & 0 & $34.7 \%$ & $34.7 \%$ & $26.5 \%$ \\
\hline
\end{tabular}

${ }^{*}$ Pseud.- Pseudomonas aeruginosa, Acinet.- Acinetobacter spp. Gen- Gentamicin, AK- Amikacin, CIP- Ciprofloxacin, CAZ-Ceftazidime, NITNitrofurantoin, TOB- Tobramycin, IMI Imipenem, PIT-Pipercillin/ Tazobactam 


\begin{tabular}{|c|c|c|c|c|c|c|c|c|c|c|}
\hline \multirow[b]{2}{*}{ S.No. } & \multirow{2}{*}{$\begin{array}{l}\text { Place of study } \\
\text { and year }\end{array}$} & \multirow[b]{2}{*}{ Author } & \multirow{2}{*}{$\begin{array}{l}\text { Org. Prevalence } \\
(\%)\end{array}$} & \multicolumn{7}{|c|}{ Antibiotics sensitivity \% } \\
\hline & & & & $G E N^{*}$ & $N X$ & COT & CIP & VAN & NIT & $L Z$ \\
\hline \multirow[t]{3}{*}{1.} & \multirow{3}{*}{$\begin{array}{l}\text { Muzaffarnagar } \\
(2015)\end{array}$} & \multirow{3}{*}{$\begin{array}{l}\text { Rangari } \\
\text { et al. }^{18}\end{array}$} & S.A $(2 \%)$ & $83.3 \%$ & $83.3 \%$ & - & $33.3 \%$ & $100 \%$ & $100 \%$ & $100 \%$ \\
\hline & & & CONS (3\%) & $77.8 \%$ & $66.7 \%$ & - & $11.11 \%$ & $77.8 \%$ & $100 \%$ & $77.8 \%$ \\
\hline & & & En $(20 \%)$ & $11.7 \%$ & $25 \%$ & - & $6.7 \%$ & $93.3 \%$ & $91.7 \%$ & $93.3 \%$ \\
\hline \multirow[t]{3}{*}{2.} & \multirow{3}{*}{$\begin{array}{l}\text { Karnataka } \\
(2018)\end{array}$} & \multirow{3}{*}{$\begin{array}{l}\text { Naik } \\
\text { et al. }^{20}\end{array}$} & S.A $(15.3 \%)$ & $73.3 \%$ & $26.7 \%$ & $26.7 \%$ & $46.7 \%$ & $100 \%$ & $93.3 \%$ & $100 \%$ \\
\hline & & & CONS $(40.81 \%)$ & $77.5 \%$ & $55 \%$ & $17.5 \%$ & $75 \%$ & $100 \%$ & $97.5 \%$ & $100 \%$ \\
\hline & & & En $(43.87 \%)$ & $72.1 \%$ & $51.2 \%$ & $23.25 \%$ & $53.9 \%$ & $100 \%$ & $90.7 \%$ & $100 \%$ \\
\hline \multirow[t]{3}{*}{3.} & \multirow{3}{*}{$\begin{array}{l}\text { Punjab } \\
\text { (2016) }\end{array}$} & \multirow{3}{*}{$\begin{array}{l}\text { Bandhan } \\
\text { et al. }{ }^{21}\end{array}$} & S.A $(11.5 \%)$ & - & $17 \%$ & $37 \%$ & - & $100 \%$ & $87 \%$ & $100 \%$ \\
\hline & & & CONS $(5.7 \%)$ & - & $25 \%$ & $100 \%$ & - & $100 \%$ & - & $100 \%$ \\
\hline & & & En $(13.5 \%)$ & - & $28 \%$ & $14 \%$ & - & $100 \%$ & $100 \%$ & $100 \%$ \\
\hline \multirow[t]{3}{*}{4.} & \multirow{3}{*}{$\begin{array}{l}\text { Delhi } \\
\text { (Our study) }\end{array}$} & \multirow[t]{3}{*}{-} & S.A $(0.35 \%$ & $90 \%$ & - & $50 \%$ & $20 \%$ & $90 \%$ & $90 \%$ & $100 \%$ \\
\hline & & & CONS $(1.44 \%)$ & $41.5 \%$ & - & $56 \%$ & $12.2 \%$ & $85.4 \%$ & $85.4 \%$ & $85.4 \%$ \\
\hline & & & $\operatorname{En}(3.67 \%)$ & $22.1 \%$ & & $50.9 \%$ & $9.6 \%$ & $65.4 \%$ & $50.9 \%$ & $81.7 \%$ \\
\hline
\end{tabular}

*S.A- Staphylocccusaureus, CONS- Coagulase negative Staphylocccus, En- Enteococcus Spp. GEN- Gentamicin, NX-Norfloxacin, COTCotrimoxazole, CIP- Ciprofloxacin, VAN- Vancomycin, NIT- Nitrofurantoin, LZ-Linezolid. GEN ${ }^{*}$ - High level Gentamicin for Enterococcus

spp., S. aureus and CONS were highly resistant to penicillin, gentamicin, erythromycin, and ciprofloxacin (As per the clinical and laboratory standards institute (CLSI) guidelines Penicillin and Erythromycin are included in Group A antibiotics for Staphylococcus and Enterococcus. Hence the author mentioned in discussion have probably used a panel of antibiotics that included this two drugs as well) while all of them were $100 \%$ sensitive to vancomycin, linezolid, and rifampicin. Comparative resistance pattern of different Fermenters in the different study is given in Table 7.

Resistance to antimicrobials has been noted ever since the first use of these agents and is increasing with each passing day. Empirical treatment for nosocomial UTIs with multi-drug resistant isolates remains challenging with many authorities recommending parenteral carbapenems, especially where extended-spectrum beta-lactamases (ESBL) producing isolates are involved. ${ }^{5}$ The increasing rates of resistance to uropathogenic isolate warrants evaluation of other antimicrobials such as fosfomycin which can safely be given orally and is highly effective against many uropathogens. The results of this study will benefit clinicians to know the local pattern of antimicrobial susceptibilities and formulate the empirical antibiotic strategies in patients presenting with UTIs. ${ }^{1}$

\section{CONCLUSION}

E. coli, Pseudomonas spp., Klebsiella spp. and Enterococcus spp. are the predominant pathogens causing urinary tract infection. Gram-negative fermenters showed the highest sensitivity to carbapenems and Gram-positive to glycopeptides and linezolid. There is increasing resistance to, and nitrofurantoin noted in our study that is frequently considered drugs of choice for empiric therapy. It is important to determine trends in antimicrobials susceptibilities, to formulate local antibiotics policy that will guide the clinicians regarding the empirical choice for UTI to prevent misuse or overuse of antibiotics.

\section{CLINICAL SIGNIFICANCE}

Because of the emerging resistance to the available group of antimicrobials, regular monitoring of resistance pattern is essential for the clinicians to choose for the best empiric therapy

\section{REFERENCES}

1. Khan IU, Mirza IA, Ikram A. Antimicrobial Susceptibility Pattern Of Bacteria Isolated from patients with Urinary Tract infection. JCPSP 2014; 24(11):840-844

2. Kaira SS, Pai C. Study of Uropathogenic Escherichia coli with special reference to its virulence factors. Int J Community Med Public Health. 2018;5:177-181.

3. Khameneh ZR, Afshar AT. Antimicrobial susceptibility pattern of urinary tract pathogens. Saudi J Kidney Dis Transpl 2009;20:251-253

4. Bean DC, Krahe D, Wareham DW. Antimicrobial resistance in community and nosocomial isolates of Escherichia coli urinary tract isolates. Ann ClinMicrobiolAntimicrob 2008;7:13

5. Multi Drug Resistance Gram Negative Bacilli- a review. J chemother 2017;29(sup 1):2-9

6. Panda PS, Chaudhary U, Dube SK. Study of biofilm production and antimicrobial sensitivity pattern of uropathogens in a tertiary care hospital in North India. Int J Community Med Public Health 2016;3:2421-2426

7. Farajnia S, Alikhani MY, Ghotaslou R, Naghili B, Nakhlband A. Causative agents and antimicrobial susceptibilities of urinary tract infections in the northwest of Iran. IJID 2009;13:140-144

8. Prakash D, Saxena RS. Antimicrobial susceptibility pattern of human pathogenic bacteria related to Enterobacteriaceae family causing urinary tract infection. Advances in Applied Science research 2013;4(3):98-104

9. Prakash D, Saxena RS. Distribution and Antimicrobial Susceptibility Pattern of Bacterial Pathogens Causing Urinary Tract Infection in Urban Community of Meerut City, India. ISRN Microbiology 2013 
10. Ronald A. The etiology of urinary tract infection: traditional and emerging pathogens. Am J Med 2002; 113:14-19

11. Tessema B, Kassu A, Mulu A, Yismaw G. Predominant isolates of urinary tract pathogens and their susceptibility patterns in Gonder University Teaching Hospital, Northwest Ethiopia. Ethio Med J 2007;45:61-67

12. Majumdar D, Sharan H, Singh DN. Fluoronquinolone resistant Escherichia Coli and Klebsiella spp. in community acquired urinary tract infections in rural Kanpur, India. Journal of Clinical and Diagnostic research 2012;6:978981

13. Eshwarappa M, Dosegowda R, Aprameya IV, Khan MW, Kumar PS. Clinico-microbiological profile of urinary tract infection in south India. Indian J Nephrol 2011;21:30-36

14. Malini A, Deepa EK, Gokul BN, and Prasad SR. Nonfermenting Gram-Negative Bacilli Infections in a Tertiary Care Hospital in Kolar, Karnataka. J Lab Physicians 2009 Jul-Dec; 1(2):62-66.

15. Panda PS, Chaudhary U, Dube SK. Study of biofilm production and antimicrobial sensitivity pattern of urinary tract infection causing Acinetobacter baumannii and Pseudomonasaeruginosain a tertiary care hospital. Int J Health Allied Sci 2015;4:272-273.
16. Lee KW, Lee ST, Cho H. Burkholderiacepacia causing nosocomial UTI in Children child kidney Dis 2015;19:143-147.

17. Nimri L, Sulaiman M, Hani OB. Community-acquired urinary tract infections caused by Burkholderiacepacia complex in patients with no underlying risk factor. JMM case reports. 2017 Jan 31;4(1).

18. Rangari AA, Sharma S,Tyagi N, Singh P, Singh G, Thakur R. Antibiotic Susceptibility Pattern of Bacterial Uropathogens Isolated from Patients at a Tertiary Care Hospital in Western Uttar Pradesh of India.Int.J.Curr.Microbiol.App. Sci 2015;4(10):646-657.

19. Naik TB, Lavanya J,Upadhya A, Mane V. Gram positive uropathogens and their antibiogram: Data analysis at a tertiary care hospital in Karnataka. IJMR, January-March 2018;5(1):71-75.

20. Badhan R, Singh DV, Badhan LR, Kaur A. Evaluation of bacteriological profile and antibiotic sensitivity patterns in children with urinary tract infection: A prospective study from a tertiary care center. Indian J Urol 2016;32:50-56

21. Bhatt P, Jagani R, Ranjan P, Namaji MAA, Rathi K M. Antimicrobial Resistance Pattern of Bacterial Isolates from Urinary Tract Infections at a Tertiary Care Centre. Int. J. Curr. Microbiol. App. Sci 2017;6(1): 175-183. 